\title{
Graphene oxide modified carbon fiber prepregs: A mechanical comparison of the effects of oxidation methods
}

\author{
V. Acar ${ }^{1}$, S. Erden ${ }^{2}$, M. Sarlkanat ${ }^{2}, Y_{\text {Seki }}{ }^{3}, H$. Akbulut $^{1}$, M. Ö. Seydibeyoğlu ${ }^{4 *}$ \\ ${ }^{1}$ Ataturk University, Department of Mechanical Engineering, Erzurum, Turkey \\ ${ }^{2}$ Ege University, Department of Mechanical Engineering, Izmir, Turkey \\ ${ }^{3}$ Dokuz Eylul University, Department of Chemistry, Izmir, Turkey \\ ${ }^{4}$ Izmir Katip Celebi University, Department of Materials Science and Engineering, Izmir, Turkey
}

Received 25 March 2020; accepted in revised form 15 May 2020

\begin{abstract}
The objective of this study is to understand the significance of graphene oxide type for the improvement of mechanical properties of carbon fiber reinforced epoxy composites. Modified epoxy systems were prepared by adding two different graphene oxide nanoparticles prepared by the modified Hummers method (GOH) and Laachachi method (GOL). In the second stage, carbon fiber reinforced epoxy composites were produced using prepreg manufacturing technique. X-ray Photoelectron Spectroscopy characterizations of the pure graphene and modified graphene nanoparticles (GOH and GOL) were performed to confirm the oxidation of the nanoparticles. The morphology of the nanocomposite epoxy resin was investigated with scanning electron microscopy. Mechanical tests were conducted with composites to determine the properties of the final materials. It was observed that the addition of the GOH improved the longitudinal tensile and flexural strength values by 41 and 33\%, respectively. Interlaminar shear strength (ILSS) values of epoxy/carbon fiber significantly increased up to $58 \%$ with $\mathrm{GOH}$ addition. Moreover, the results show that nano-enhanced resins could be a key component for many composites, and it can be a suitable material for long term usage and resistance of sudden failure of composites.
\end{abstract}

Keywords: nanocomposites, graphene oxide, hummers method, prepreg, mechanical properties

\section{Introduction}

Carbon fiber-reinforced composites that are widely used in aerospace, automotive, and other industries are growing with an exponential rate [1-3]. Carbon fiber has important advantages because of its high strength, specific fatigue behavior, and low density $[4,5]$. The interlaminar properties are key factors for the high performance of carbon fiber composites [6, 7]. The interaction between the fiber and neat epoxy is always a problem for many composite systems, including other fibers. The fiber/matrix interaction can be improved by using physical and chemical treatments to achieve enhanced interfacial and interlaminar properties. One of these treatments is to modify the matrix material used in the manufacturing of the composite [8]. Nanoparticles are one of the most promising solutions to modify the matrix material. Carbon nanomaterials have been used to improve the mechanical and thermal properties of composites. In this context, Garcia et al. [9] used carbon nanotubes (CNT) to improve the fracture toughness of carbon fiber epoxy composite. The bridge effect helped to connect the laminates better and stronger. Furthermore, it was stated that the study could be improved with surface modification of carbon nanotubes. Similarly, the effect of CNT on the carbon fiber epoxy composites for mechanical improvement was studied by Yokozeki et al. [10] It was observed that the mechanical properties were improved to a certain extent. Therefore, CNT materials were successfully 
used for the enhancement of the structural properties of composites.

Carbon nanomaterials gained more and more importance with the fabrication of a few-layer graphene by Novoselov et al. [11]. The hybrid composite of graphene nanoplatelets (GNP) with the long fiber has been a new era in the composite scientific community and the industries for certain applications. Some studies based on graphene-based composites showed that the mechanical properties such as fracture toughness, impact resistance, flexural and tensile strengths had been significantly increased because of the superior properties of the graphene incorporated composite [12-17]. Moreover, it was also shown that the thermal stability and conductivity had been significantly enhanced with graphene nanoparticles [18-20]. The previous studies have clearly evidenced that the strength of composite materials was improved with the inclusion of carbon nanomaterials. It has been explained by the enhanced adhesion of the fibers to the matrix material or improved mechanical properties of the matrix material due to carbon nanomaterials. As regarding this direction, specific nanostructures can be functionalized using amine, hydroxyl, carboxyl, and epoxy groups to improve the adhesion of the carbon nanomaterials to the carbon fiber composites.

In this study, the effects of oxidation methods of graphene oxides $(\mathrm{GO})$ for use in the matrix modification on the mechanical properties of carbon fiber reinforced epoxy prepreg composites were investigated with two different graphene oxides. The first GO was obtained by using the Modified Hummers Method [21], while the second GO was obtained using the Laachachi Method [22]. In the preliminary study conducted by our research group [23], ILSS performances of GO modified prepregs were studied. In the present study, the investigations were expanded: (i) characterizations of GO particles and GO modified carbon fiber prepregs were performed, and (ii) mechanical analyses were detailed. In this context, GO particles were characterized by XPS and SEM. Then, GO reinforced epoxies were prepared, and the dispersion efficiency was investigated by SEM observations. Finally, mechanical tests were performed, and longitudinal/transverse tensile strengths, flexural strength, and interlaminar shear strength (ILSS) results were evaluated.

\section{Materials and methods}

\subsection{Materials}

Carbon fiber (CF) was provided by DowAksa Advanced Composites Company (Turkey) with a specific code AKSACA-42. The carbon fibers were $12 \mathrm{~K}$, which is a standard type for carbon fibers with $4200 \mathrm{MPa}$ tensile strength. Huntsman Araldite ${ }^{\circledR}$ LY 1564 SP and Aradur ${ }^{\circledR}$ XB 3486 (USA) were chosen as the prepreg epoxy system components. GOs were obtained by two specific methods. One of the GO types $(\mathrm{GOH})$, produced by Modified Hummers Method, was obtained from raw graphite material. The other type of the GO (GOL) was achieved by the Laachachi Oxidation Method of commercial type graphene provided by Graphene Laboratories Inc. (USA) with an $8 \mathrm{~nm}$ average length. Additionally, sulfuric acid $\left(\mathrm{H}_{2} \mathrm{SO}_{4}, \geq 95 \%\right)$, nitric acid $\left(\mathrm{HNO}_{3}\right.$, $65 \%)$, hydrogen peroxide $\left(\mathrm{H}_{2} \mathrm{O}_{2}, 30 \%\right)$, potassium persulfate $\left(\mathrm{K}_{2} \mathrm{~S}_{2} \mathrm{O}_{8}, \geq 99 \%\right)$ hydrochloric acid (HCI, $37 \%$ ), ethanol $\left(\mathrm{C}_{2} \mathrm{H}_{6} \mathrm{O}, \geq 99.8 \%\right.$ ), phosphorus pentoxide $\left(\mathrm{P}_{2} \mathrm{O}_{5}, \geq 99 \%\right)$, potassium permanganate $\left(\mathrm{KMnO}_{4}\right.$, $\geq 99 \%)$ and acetone $\left(\mathrm{C}_{3} \mathrm{H}_{6} \mathrm{O}, \geq 99.9 \%\right)$ were used in the process of graphene oxidation.

\subsection{Oxidation methods of graphene nanoplatelets}

Commercial type graphene nanoplatelets were oxidized by the Laachachi method to create functional groups on the surface [22]. The same procedure as ref. [22] was followed for the oxidation of commercial graphene nanoplatelets in this study. Briefly, the commercial graphene $(0.75 \mathrm{~g})$ was stirred in ethanol $(200 \mathrm{ml})$ in order to prevent an agglomeration and obtain separated sheets. Then, the graphene was added to an acidic solution that includes $\mathrm{H}_{2} \mathrm{SO}_{4}$ and $\mathrm{HNO}_{3}(250 \mathrm{ml}, 3: 1$ by volume, respectively), and the mixture was sonicated in an ultrasonic bath for $7 \mathrm{~h}$ at $60^{\circ} \mathrm{C}$. Afterward, the mixture was diluted by a vacuum filtration method using deionized water and a filter paper. Finally, the treated graphene was dried in an oven.

The other type of GOs was achieved by means of reduction of graphite oxide. Graphite powder was used in order to synthesize GO by a modified Hummers Method, including the peroxidation step. Thus, oxidation treatment was carried out to improve the whole oxidation of graphite material, as presented by Sreeprasad et al. [21]. In brief, the graphite powder 
( $3 \mathrm{~g}$ ) was added to the $\mathrm{H}_{2} \mathrm{SO}_{4}$ solution that consists of $\mathrm{H}_{2} \mathrm{SO}_{4}\left(12.5 \mathrm{ml}, \mathrm{K}_{2} \mathrm{~S}_{2} \mathrm{O}_{8}(2.5 \mathrm{~g})\right.$, and $\mathrm{P}_{2} \mathrm{O}_{5}(2.5 \mathrm{~g})$ for peroxidation of the graphite. After a while, the solution was diluted using a vacuum filtration method with distilled water $(500 \mathrm{ml})$. Then, the preoxidized graphite was added to the $\mathrm{H}_{2} \mathrm{SO}_{4}$ solution $(115 \mathrm{ml})$, and $\mathrm{KMnO}_{4}(15 \mathrm{~g})$ was added slowly into the solution. After that, $250 \mathrm{ml}$ of distilled water was added, and the mixture was stirred. Thereafter, $30 \% \mathrm{H}_{2} \mathrm{O}_{2}$ $(12.5 \mathrm{ml})$ and distilled water $(750 \mathrm{ml})$ were added, and the mixture was kept for a day $(24 \mathrm{~h})$. Then, the solution was centrifuged and washed with $\mathrm{HCl}$ solution and distilled water. Afterward, the obtained solid material was dried, and the dilution and dialyzing treatments were conducted as presented by Sreeprasad et al. [21].

\subsection{Matrix modifications with the graphene oxides}

The dispersion of nanoplatelets in epoxy resin was the same for both the graphene oxides. The modification treatment consisted of two parts, adding a certain amount of graphene oxide into the resin and dispersing the graphene oxide in the resin. The amount of GO was determined as $0.1 \mathrm{wt} \%$ to prepare the modified resin. Therefore, that amount of GO was sonicated in acetone, which is a useful tool for the graphene dispersion in the resin, using an ultrasonic homogenizer (Hielscher UP400s, Germany) in order to prevent an agglomeration of GO sheets. Subsequently, the mixture was placed in an oven at $80^{\circ} \mathrm{C}$ to remove acetone. Afterward, the predetermined amount of epoxy resin was added into the beaker for the preparation of GO/epoxy composites. The GO/ epoxy mixture was sonicated using the ultrasonic homogenizer at $90 \mathrm{~W}$ for 15 minutes in an iced water bath and then, mechanically stirred with the hardener in the weight ratio (percent by weight) of 100:34 as specified by the manufacturer's suggestion of the ratio of the epoxy resin to the hardener [24]. Finally, $\mathrm{GO} /$ epoxy modified matrix materials were prepared to use in the prepreg manufacturing process with carbon fiber for the two different graphene oxides (GOL and $\mathrm{GOH}$ ).

\subsection{Preparation of GO - epoxy/carbon fiber prepregs}

It is known that the word 'prepreg' comes from 'preimpregnated' and it is a composite material manufacturing method. In this technique, continuous fibers

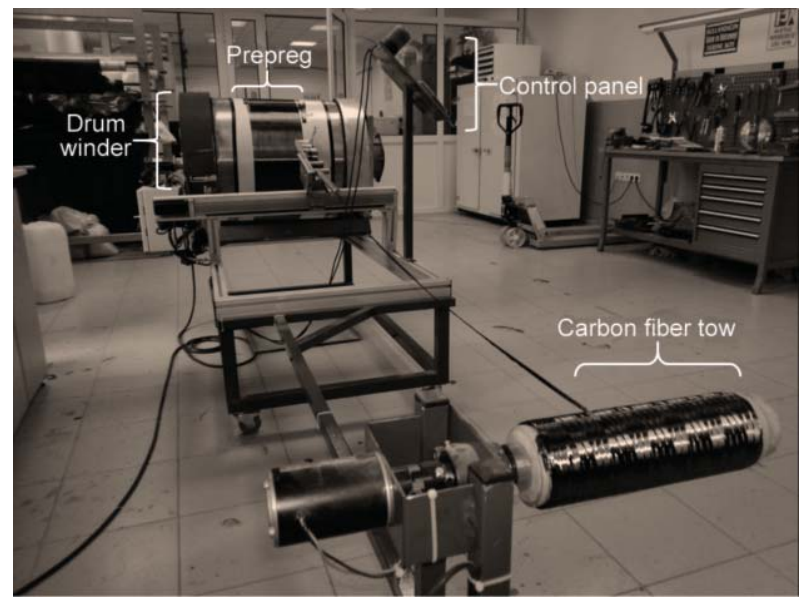

Figure 1. The prepreg machine used in the study.

are pre-impregnated with a certain amount of resin. The composite structure is cured until a point defined ' $\mathrm{B}$ - Stage' in which entire polymerization is not completed. Prepregs are stored in cold storage that keeps the resin in the gel state. Hence, the producer can subsequently continue the curing process to manufacture composite materials in various conditions, containing angle ply or unidirectional laminated composites.

In the study, a lab-scale prepreg machine, known as 'drum winder', was set up in the laboratory. The prepreg machine can be seen in Figure 1. Prepregs with neat epoxy $($ Epoxy/CF) were primarily prepared and then, GOL-Epoxy/CF and GOH - Epoxy/ CF prepregs were prepared and stored in a deep freeze, respectively. The prepreg thickness was measured as $0.140 \mathrm{~mm}$, averagely. The prepreg mold to manufacture laminated composites was designed according to the ASTM D-3039 standard. Afterward, laminated composites were manufactured in the mold at $120^{\circ} \mathrm{C}$ and pressure of 5 bar for 30 minutes in a hot press by pressing seven prepregs to obtain $1 \mathrm{~mm}$ of thickness for $0^{\circ}$ unidirectional orientation as stated in the standard. The process chart of the study can be seen in Figure 2.

\subsection{Characterizations}

The composition of the elements in the surface region of the deposited layers was investigated by XPS on a Specs ESCA spectrometer (Germany) equipped with a non-monochromatic $\mathrm{Mg} \mathrm{K} \alpha$ radiation source at a power of $200 \mathrm{~W}$ and EA 200 hemispherical electrostatic energy analyzer. The base pressure in the sample chamber was controlled in the range of $10^{-9}$ $10^{-10}$ torr. The pass energies were 96 and $48 \mathrm{eV}$ for the survey- and high-resolution spectra, respectively. 


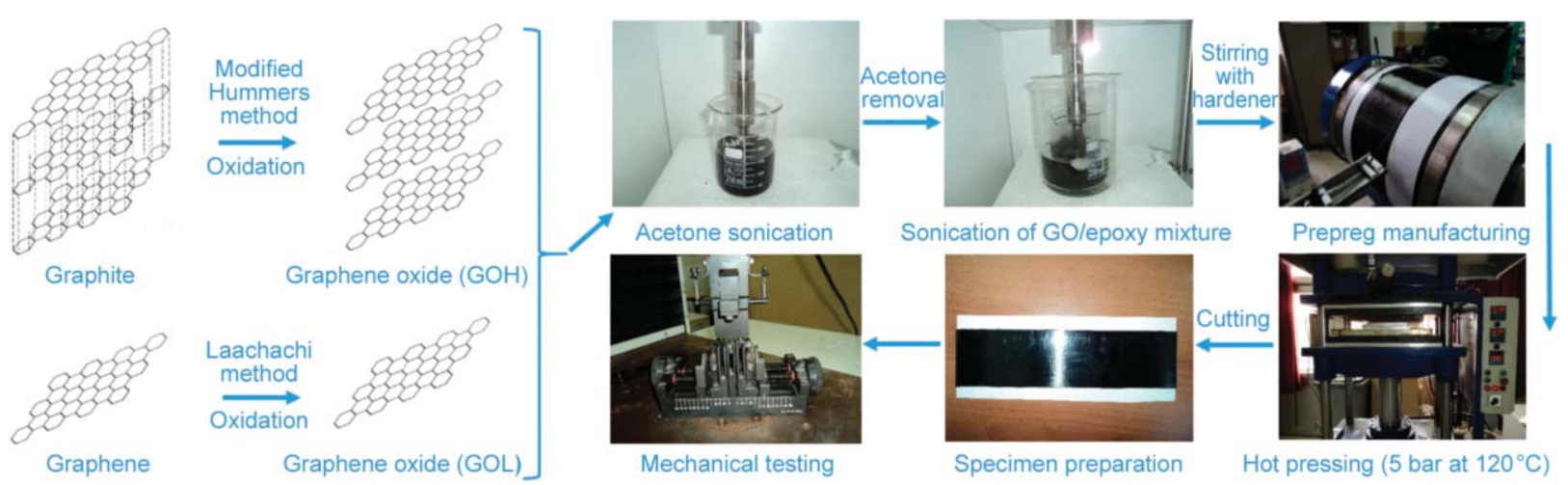

Figure 2. The process chart of the study.

The deconvolution of the XPS spectra was conducted by fitting the data with Gaussian-Lorentzian functions. SEM images of samples were taken with FEI Quanta FEG 250 scanning electron microscope at accelerating voltages of 5 and $10 \mathrm{kV}$. ILSS tests were conducted with ASTM D-2344 on a universal testing machine (Autograph AG-IS Shimadzu Corp., Japan). The tests were carried out at least six times. Flexural tests were carried out according to ASTM D-790 on the universal testing machine. At least three samples were measured, and the results were averaged. The longitudinal and transverse tensile strengths were tested in accordance with ASTM D-3039. At least three specimens were tested to ensure the repeatability of the results.

\section{Results and discussions}

\subsection{XPS results}

The surface compositions of graphene nanoplatelet, GOL, and GOH were given in Table 1. C1s content of graphene nanoplatelet was determined to be $90.15 \%$. After the oxidation process of graphene nanoplatelet by using the Laachachi Method, the carbon content decreased from 90.15 to $80.65 \%$, and the oxygen content increased significantly from 9.85 to $19.35 \%$. A similar trend was observed with the modified Hummers method. While the $\mathrm{C}$ content decreased from 90.15 to $71.15 \%$, O content increased considerably from 9.85 to $28.85 \%$. The Laachachi

Table 1. The surface compositions of graphene (G), graphene oxide by Laachachi method (GOL) and graphene oxide by Modified Hummers method (GOH).

\begin{tabular}{|l|c|c|c|}
\hline \multirow{3}{*}{ Samples } & \multicolumn{3}{|c|}{$\begin{array}{c}\text { Elements } \\
{[\%]}\end{array}$} \\
\cline { 2 - 4 } & C1s & O1s & O/C ratio \\
\hline G & 90.15 & 9.85 & 0.11 \\
\hline GOL & 80.65 & 19.35 & 0.24 \\
\hline GOH & 71.15 & 28.85 & 0.41 \\
\hline
\end{tabular}

method has provided a significant increase in the O1s content. However, the Hummers method has provided more effective oxidation than the other chemical oxidation. This is the result of better interaction between graphene oxide layers and epoxy resin. As the oxidation level increases, the mechanical performance of the composites increases as the interface becomes much stronger as a result of higher $\mathrm{O}$ content. The $\mathrm{O} / \mathrm{C}$ atomic ratio for $\mathrm{G}$ was obtained to be 0.11 . After graphene oxide is fabricated by Laachachi method and Hummers method, this ratio increased to 0.24 and 0.41 , respectively. It can be reported that graphene oxide fabricated by a modified Hummers method is more hydrophilic than that of Laachachi method. According to a recent study by Jiang et al. [25], it is stated that the addition of graphene oxide particles in the polyurethane carbon fiber composites increased the $\mathrm{O} / \mathrm{C}$ atomic ratio, which is consistent with our results. It is known that the higher content of oxygen functional groups on the surface of the carbon fiber can improve the adhesion properties of carbon fiber composites, probably due to higher electronegativity and polar characteristics at the interface between the carbon fiber surface and the matrix [26]. This study exhibited that epoxy matrix modification with graphene oxide prepared by a modified Hummer method may be an option to improve the adhesion properties of carbon fiber and epoxy.

C1s core level spectra of samples were deconvoluted into three distinct components. Binding energies of functional groups were presented in Table 2. The amount of functional groups [\%] was presented in Table 3. As can be seen from Table 3, the amount of $\mathrm{C}=\mathrm{O}$ functional groups is almost not present on the surface of the samples. Graphene has the highest $\mathrm{C}-\mathrm{C} / \mathrm{C}-\mathrm{H}$ group and the lowest $-\mathrm{C}-\mathrm{OH} /-\mathrm{C}-\mathrm{OR}$ group. After oxidation of graphene, while the amount of $\mathrm{C}-\mathrm{C} / \mathrm{C}-\mathrm{H}$ groups decreased, the amount of 
$-\mathrm{C}-\mathrm{OH} /-\mathrm{C}-\mathrm{OR}$ groups increased considerably. It is seen that $\mathrm{GOH}$ has the lowest $\mathrm{C}-\mathrm{C} / \mathrm{C}-\mathrm{H}$ groups and the highest $-\mathrm{C}-\mathrm{OH} /-\mathrm{C}-\mathrm{OR}$ groups.

Table 2. Binding energies of functional groups.

\begin{tabular}{|c|c|}
\hline $\begin{array}{c}\text { Binding energy } \\
{[\mathrm{eV}]}\end{array}$ & Functional groups \\
\hline 284.7 & $\mathrm{C}-\mathrm{C} / \mathrm{C}-\mathrm{H}$ \\
\hline 286.5 & $-\mathrm{C}-\mathrm{OH} /-\mathrm{C}-\mathrm{OR}$ \\
\hline 286.2 & $-\mathrm{COOH} /-\mathrm{COOR}$ \\
\hline
\end{tabular}

Table 3. The amount of functional groups for samples.

\begin{tabular}{|l|c|c|c|}
\hline & $\begin{array}{c}-\mathbf{C}-\mathbf{C} / \mathbf{C}-\mathbf{H} \\
{[\mathbf{\%}]}\end{array}$ & $\begin{array}{c}-\mathbf{C}-\mathbf{O H} / \mathbf{C}-\mathbf{O R} \\
{[\%]}\end{array}$ & $\begin{array}{c}-\mathbf{C O O H} / \mathbf{C O O R} \\
{[\%]}\end{array}$ \\
\hline $\mathrm{G}$ & 94.12 & 5.64 & 0.26 \\
\hline $\mathrm{GOL}$ & 86.71 & 13.10 & 0.19 \\
\hline $\mathrm{GOH}$ & 73.16 & 26.67 & 0.17 \\
\hline
\end{tabular}

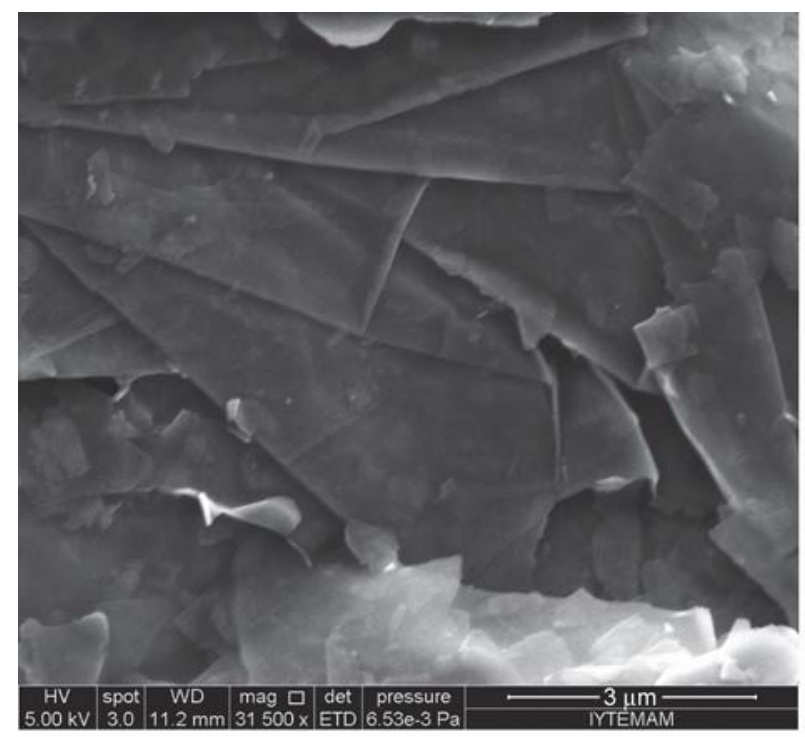

a)

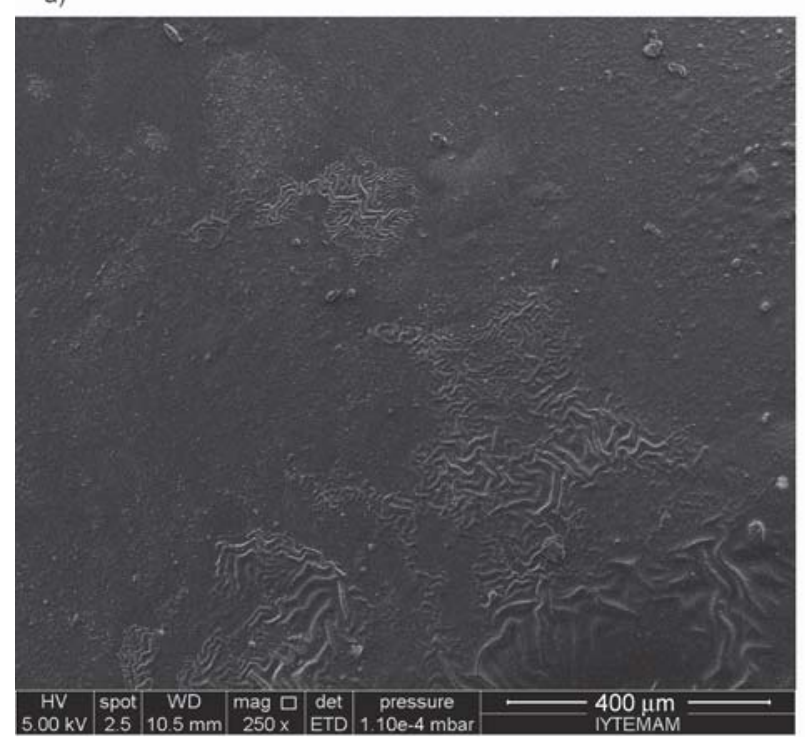

c)

\subsection{SEM observations}

Figure $3 \mathrm{a}$ and $3 \mathrm{~b}$ show the graphene oxide platelets, GOL, and GOH particles, respectively. It is clearly seen that the graphene oxide particles have quite similar shapes in terms of length and width values. These images show that graphene oxides could be clearly observed in the study, and graphene oxide production was supported by the oxygen content obtained via XPS analysis. It was one of the most important parts of this study to understand the reinforcing mechanisms of graphene oxide nanoplatelets for epoxy-carbon fiber prepreg studies. Figure $3 \mathrm{c}$ shows , and it was inferred from SEM images that there were agglomerates of graphene oxide sheets in the epoxy resin, which negatively affects the reinforcing capability in the composite structures. The agglomeration of nanoparticles in polymer matrices is one

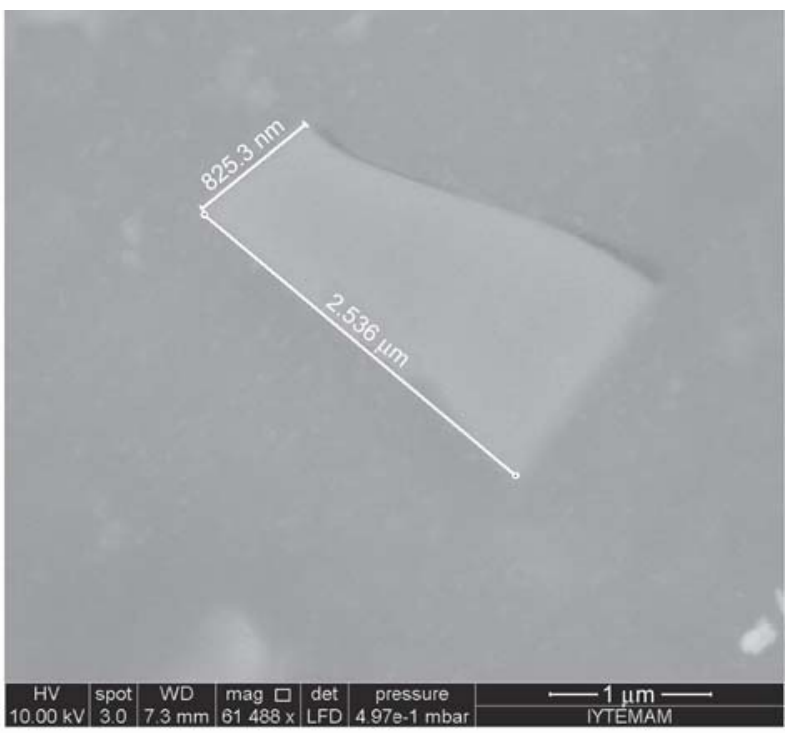

b)

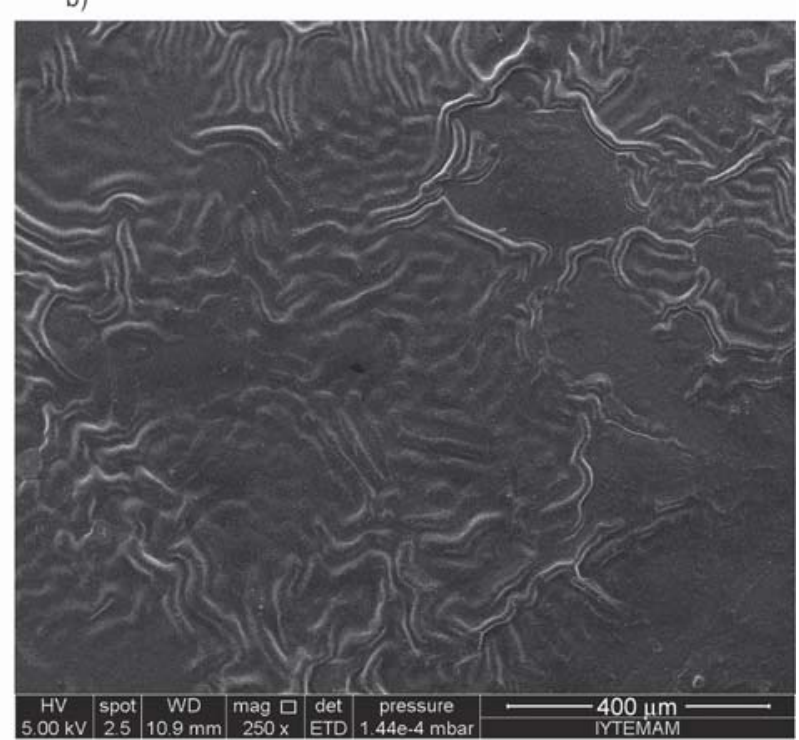

d)

Figure 3. SEM images of a) GOL b) GOH c) GOL dispersed epoxy d) GOH dispersed epoxy. 
of the key problems in the nanotechnology field, which prevents the rapid commercialization of nanotechnology [27-29]. These aggregates of graphene platelets behave as micron-sized fillers, which lead to less increase in the mechanical strength of Epoxy /CF composite.

Figure 3d shows excellent dispersed GOH platelets in epoxy resin. The differences in oxygen contents of the graphene oxides affect the dispersion of the nanomaterials in polymer systems. The surface modification is a common technique that is used for nanocomposite preparation [30,31]. Based on these previous findings and conducted XPS studies, it is considerably inferred that $\mathrm{GOH}$ is preferred over GOL in the preparation of nanocomposites with epoxy. This good dispersion does not only affect epoxy nanocomposite structure, but also it is very critical for the reinforcement of the final carbon fiber/epoxy composites [32]. The detailed mechanical analyses clearly showed that GOH further improves the mechanical performance of the composites rather than GOL.

\subsection{Interlaminar shear strength (ILSS)}

For the strength of the composite material, the fibermatrix-adhesion is an important parameter to characterize the quality and strength of the composite. A parameter allowing the quantification of the fibermatrix-adhesion is the ILSS [33]. As it is not easy to combine different materials in the composite, the interphase plays a key role in the composite materials [33]. The interfacial adhesion between fibers and matrix directly affects the interlaminar mechanics, and thus ILSS test is the one of the most common tests used for the composite materials [34-37]. In this study, two different graphene oxides were used in order to improve the interlaminar strength of the composite. ILSS values of prepreg composites are presented in Figure 4. ILSS value of Epoxy/CF was determined to be $21.1 \pm 2.8 \mathrm{MPa}$. GOL and $\mathrm{GOH}$ addition into the epoxy matrix increased the ILSS value of Epoxy/CF composite to $24.8 \pm 2.6$, and $33.3 \pm 4.3 \mathrm{MPa}$, respectively [23]. These values indicate a considerable increase, $17 \%$ for GOL addition and 58\% for GOH addition, in ILSS value of Epoxy/ $\mathrm{CF}$, respectively. It is clearly seen that both graphene oxides improved ILSS values of the carbon fiber epoxy prepregs. ILSS test results have exhibited that the bonding between the matrix and fiber was enhanced. Short beam shear test results have clearly shown that the graphene oxide could be an important

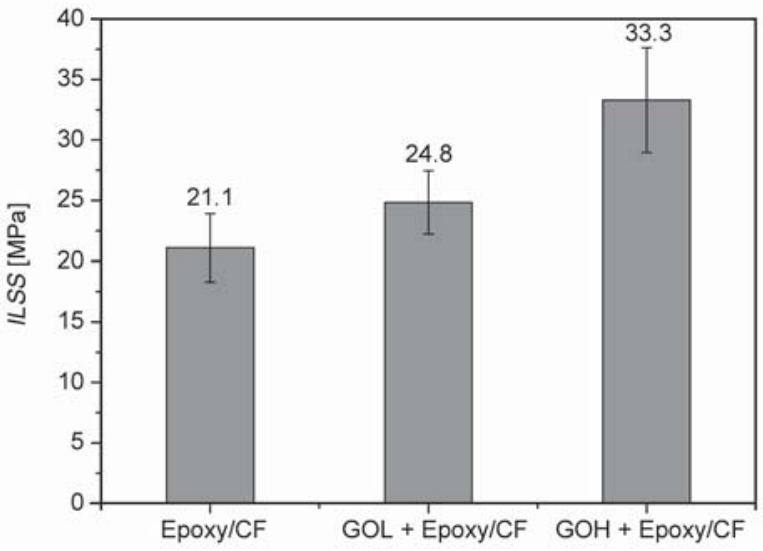

Figure 4. ILSS values of prepreg composites [23].

reinforcement material for long fiber polymer composites. As was presented in XPS and SEM studies, the high oxygen content in $\mathrm{GOH}$ and well dispersion of GOH in the epoxy have caused more increase in ILSS of GOH composites rather than GOL composites. Interlaminar forces are strongly associated with certain covalent bonds and surface chemistry. Therefore, it can be concluded that the oxygen content increases the interaction between the matrix and fibers. In the study of He et al., [38] GO prepared by a modified Hummers method was used to modify the surface of carbon fiber layers. After introducing GO flakes on carbon fabric, the ILSS value of carbon fabric-reinforced epoxy resin composite increased by $34 \%$. It was explained by the fact that functional groups present on the GO-carbon fabric surface favor the formation of bonds between carbon fibers and resin matrix [38]. This result is compatible with the results presented in our study.

\subsection{Flexural properties}

The flexural strengths of the Epoxy/carbon fiber prepreg composites are shown in Figure 5a. The flexural strength of epoxy carbon fiber prepreg composite was obtained to be $751.4 \pm 66 \mathrm{MPa}$. After the addition of GOL and GOH into epoxy resin, the flexural strength of composite increased to $862.5 \pm 70.4$ and $998.9 \pm 74.8 \mathrm{MPa}$, respectively. The flexural strength of epoxy carbon fiber prepreg composite increased by about $15 \%$ with GOL and $33 \%$ with $\mathrm{GOH}$ additions into the epoxy matrix. It can be clearly noted that the flexural strength of Epoxy/CF composite was significantly improved through graphene oxide addition into the epoxy matrix. In the study of He et al. [38], modification of the surface of carbon fiber layers with GO increased the flexural strength of carbon fabric-reinforced epoxy resin composite 

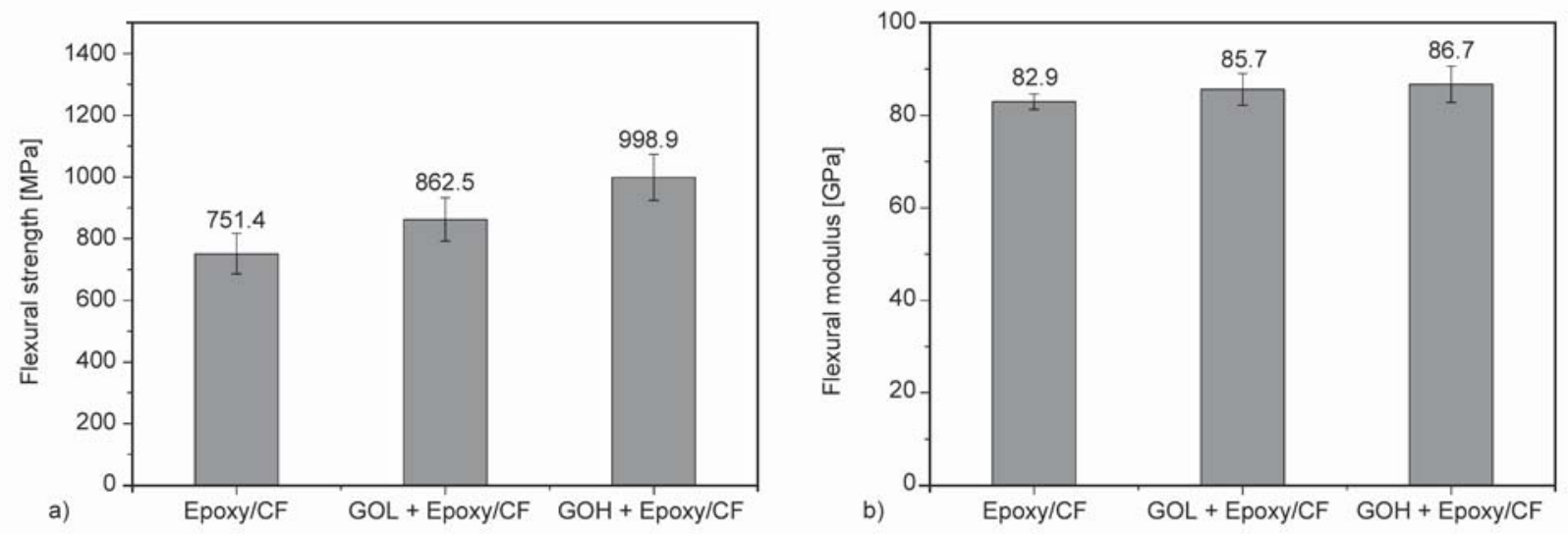

Figure 5. a) Flexural strengths and b) flexural modulus of the prepreg composites.

by $14 \%$. The flexural modulus values of the epoxy/ carbon fiber prepreg composites are given in Figure $5 \mathrm{~b}$. The flexural modulus of Epoxy/CF was obtained to be $82.9 \pm 1.7 \mathrm{GPa}$. The addition of GOL and $\mathrm{GOH}$ into the epoxy matrix increased the flexural modulus of epoxy/CF to $85.7 \pm 3.4$ and $86.7 \pm 3.9 \mathrm{GPa}$, respectively. It can be said that GOL and GOH additions into the epoxy matrix increased the flexural modulus of epoxy/CF composite by 3.3 and $4.6 \%$, respectively. It is known that ILSS is used to indirectly evaluate fiber/matrix adhesion and the overall quality of the composite material [39]. Since GOL and $\mathrm{GOH}$ addition into epoxy increased the ILSS of Epoxy/CF, a better adhesion would be expected between fiber and matrix material. Therefore, the increased flexural strength may be attributed to an increase in epoxy-carbon fiber bonding. This is probably due to increased fiber wettability [40].

\subsection{Tensile properties}

Longitudinal and transverse tensile strengths of the prepreg composites are presented in Figure 6a and $6 \mathrm{~b}$, respectively. The longitudinal tensile strength of Epoxy/CF composite was obtained to be
967.5 $\pm 56.7 \mathrm{MPa}$. After addition of GOL and $\mathrm{GOH}$ into epoxy, the longitudinal tensile strength of Epoxy/ CF increased to $1157.9 \pm 64.5$ and $1367.7 \pm 82.4 \mathrm{MPa}$, respectively. It can be reported that $\mathrm{GOH}$ addition into epoxy matrix led to a greater increase, $41 \%$, in longitudinal tensile strength of Epoxy/CF than GOL addition, 20\%. Furthermore, similar observations were observed in the transverse direction. The transverse tensile strength of Epoxy/CF was obtained to be $76.8 \pm 4.8 \mathrm{MPa}$. GOL and GOH additions increased the transverse tensile strength of Epoxy/CF by $23 \%$ (94.6 \pm 6.8$)$ and $53 \%(117.8 \pm 5.9)$, respectively. It can be noted that GOH addition into epoxy led to better longitudinal and transverse tensile strengths in the Epoxy/CF prepreg composite. This difference might result from the oxygen contents of the graphene oxides. $\mathrm{O} / \mathrm{C}$ ratio for $\mathrm{GOH}, 0.41$, is higher than that of GOL, 0.24. In order to increase the strength of composites, there are many mechanisms, including chemical interlocking mechanisms and better interface adhesion. The presence of graphene oxide may help to improve the interlocking mechanism in the interface. The thin layers of graphene oxide helped to enhance the interconnection between the fiber and matrix, and
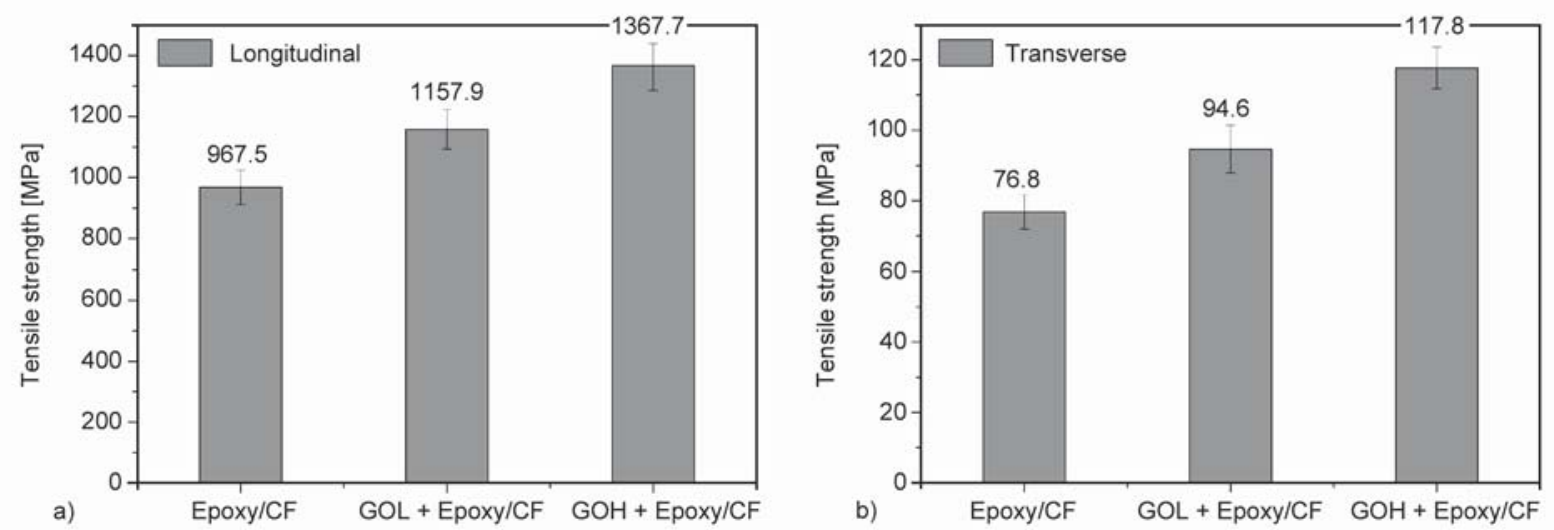

Figure 6. a) Longitudinal and b) transverse tensile strengths of the prepreg composites. 
thus, the tensile strength was improved. These results presented in this study are very critical for many unidirectional composite structures since the carbon fibers are not strong in the transverse direction. Hence, this study shows that the graphene oxides help to strengthen the carbon fiber composites in the transverse direction due to better adhesion of carbon fibers to the epoxy matrix via graphene oxide particles. Therefore, the results both in the longitudinal and transverse directions are considered promising. For example, in a study of Kim et al. [41], $0.5 \mathrm{wt} \%$ of pristine MWCNTs (pMWCNT) and silane-functionalized MWCNTs (fMWCNT) were mixed with epoxy. The tensile strengths of p-MWCNTs/epoxy/ $\mathrm{CF}$ and f-MWCNTs/epoxy/CF were obtained to be 874.6 and $883.2 \mathrm{MPa}$, which indicates an increase of 2 and 3\%, respectively. Thus, it can be inferred that the addition of graphene oxide into Epoxy/CF led to a greater increase in tensile strength than that of p-MWCNTs and f-MWCNTs.

The tensile modulus of the composites was also measured in the longitudinal direction and presented in Figure 7. The tensile modulus of Epoxy/CF was obtained to be $76.1 \pm 4.6 \mathrm{GPa}$. GOH and GOL addition into epoxy matrix increased the tensile modulus of Epoxy/CF to $81.4 \pm 4$ and $83.1 \pm 6 \mathrm{GPa}$, which indicates an increase of about 7 , and $9 \%$, respectively. With the addition of graphene oxide into the epoxy matrix, the modulus values of Epoxy/CF increased, and the composites became stiffer. Thus, the composites can withstand higher loads without any plastic deformation. This situation may be highly important for aerospace applications as aerospace materials are exposed to certain loads for a long time.

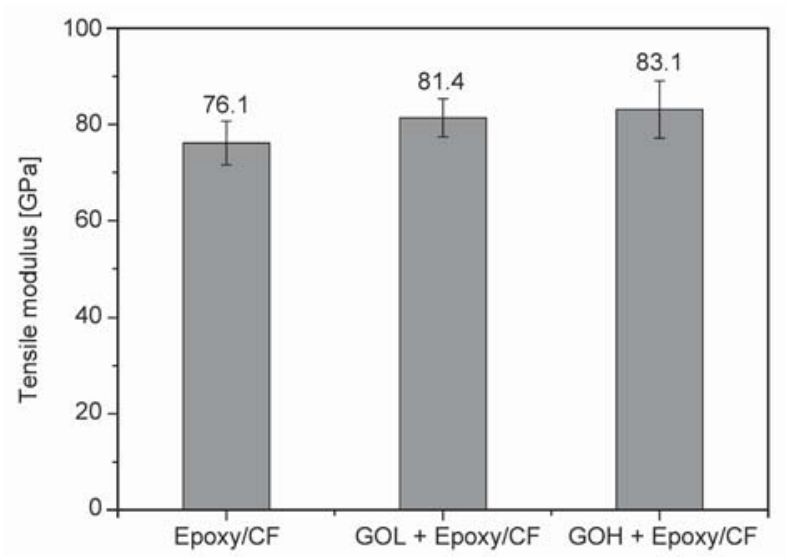

Figure 7. Tensile modulus of the prepreg composites.

\section{Conclusions}

In this study, the epoxy resin used in the preparation of carbon fiber reinforced epoxy prepreg composites was modified using graphene oxide materials. In the modification of the epoxy systems, two different graphene oxides, which synthesized by a modified Hummers method $(\mathrm{GOH})$ and Laachachi method (GOL), were added to the polymer system at a ratio of $0.1 \mathrm{wt} \%$. Subsequently, carbon fiber reinforced epoxy composites were produced using prepreg manufacturing technique, and the mechanical tests were carried out on the composites. Experimental results show that GOH improves the adhesion between the fiber and matrix better than GOL because of its higher oxygen content. When the ILSS test results were examined, GOH prepregs exhibited the greatest ILSS value. The increase in ILSS of GOL prepregs was $17 \%$, while the same increase in $\mathrm{GOH}$ prepregs was $58 \%$. According to flexural test results, although the flexural strengths of GOH and GOL prepregs were increased by almost 33 and $15 \%$, respectively, the flexural modulus negligibly changed with the graphene oxides. As for the longitudinal and transverse tensile strengths, the longitudinal tensile strengths of GOL and GOH prepregs were enhanced by 20 and $41 \%$, respectively. Similarly, the transverse tensile strengths of GOL and GOH prepregs were enhanced by 23 and $53 \%$, respectively.

Results of all mechanical analyses show that the Hummer oxidation method is a highly effective chemical treatment for graphene in composite applications. The interface enhancement is one of the core research areas of composite materials, and nanotechnology brings many effective results for material science. And this enhancement has been remarkably proven with $\mathrm{GOH}$ reinforcement by examination of mechanical test results; however, the fractured surfaces need to be examined by SEM observations to understand better the improvements in mechanical properties for further studies. The important outcome of this study is to understand that graphene oxide plays a very critical role in improving the performance of composite materials. Furthermore, the type of graphene oxide is the key parameter for the mechanical enhancement. 


\section{Acknowledgements}

The authors would like to acknowledge the financial support provided by Ataturk University Scientific Research Grant, BAP 2011/395 and Ege University Scientific Research Grant, BAP 11-MUH-083. Furthermore, the authors would like to thank Dr. Murat Alanyalığlu and Dr. Ferit Çakır for their scientific contributions.

\section{References}

[1] Li B., Zhang C-R., Cao F., Wang S-Q., Chen B., Li J-S.: Effects of fiber surface treatments on mechanical properties of $\mathrm{T} 700$ carbon fiber reinforced $\mathrm{BN}-\mathrm{Si}_{3} \mathrm{~N}_{4}$ composites. Materials Science and Engineering: A, 471, 169-173 (2007).

https://doi.org/10.1016/j.msea.2007.03.022

[2] Fjeldly A., Olsen T., Rysjedal J. H., Berg J. E.: Influence of the fiber surface treatment and hot-wet environment on the mechanical behavior of carbon/epoxy composites. Composites Part A: Applied Science and Manufacturing, 32, 373-378 (2001).

https://doi.org/10.1016/S1359-835X(00)00056-7

[3] Pittman C. U., Jiang W., Yue Z. R., Gardner S., Wang L., Toghiani H., Leon y Leon C. A.: Surface properties of electrochemically oxidized carbon fibers. Carbon, 37, 1797-1807 (1999).

https://doi.org/10.1016/S0008-6223(99)00048-2

[4] Daniel I. M., Ishai O.: Engineering mechanics of composite materials. Oxford University Press, New York (1994).

[5] Donnetand J. B., Bansal R. C.: Carbon fibers. Marcel Dekker, New York (1990).

[6] Ageorges C., Friedrich K., Ye L.: Experiments to relate carbon-fibre surface treatments to composite mechanical properties. Composites Science and Technology, 59, 2101-2113 (1999).

https://doi.org/10.1016/S0266-3538(99)00067-6

[7] Kaynak C., Orgun O., Tincer T.: Matrix and interface modification of short carbon fiber-reinforced epoxy. Polymer Testing, 24, 55-62 (2005).

https://doi.org/10.1016/j.polymertesting.2005.01.004

[8] Gan Y. X.: Effect of interface structure on mechanical properties of advanced composite materials. International Journal of Molecular Sciences, 10, 5115-5134 (2009). https://doi.org/10.3390/ijms10125115

[9] Garcia E. J., Wardle B. L., Hart A. J.: Joining prepreg composite interfaces with aligned carbon nanotubes. Composites Part A: Applied Science and Manufacturing, 39, 1065-1070 (2008).

https://doi.org/10.1016/j.compositesa.2008.03.011

[10] Yokozeki T., Iwahori Y., Ishiwata S., Enomoto K.: Mechanical properties of CFRP laminates manufactured from unidirectional prepregs using CSCNT-dispersed epoxy. Composites Part A: Applied Science and Manufacturing, 38, 2121-2130 (2007).

https://doi.org/10.1016/j.compositesa.2007.07.002
[11] Novoselov K. S., Geim A. K., Morozov S. V., Jiang D., Zhang Y., Dubonos S. V., Grigorieva I. V., Firsov A. A.: Electric field effect in atomically thin carbon films. Science, 306, 666-669 (2004).

https://doi.org/10.1126/science.1102896

[12] Rafiee M. A., Rafiee J., Wang Z., Song H. H., Yu Z-Z., Koratkar N.: Enhanced mechanical properties of nanocomposites at low graphene content. ACS Nano, 3, 3884-3890 (2009).

https://doi.org/10.1021/nn9010472

[13] Zaman I., Phan T. T., Kuan H-C., Meng Q. S., La L. T. B., Luong L., Youssf O., Ma J.: Epoxy/graphene platelets nanocomposites with two levels of interface strength. Polymer, 52, 1603-1611 (2011).

https://doi.org/10.1016/j.polymer.2011.02.003

[14] Ávila A. F., de O. Peixoto L. G. Z., Silva Neto A., de Ávila J., Carvalho M. G. R.: Bending investigation on carbon fiber/epoxy composites nano-modified by graphene. Journal of the Brazilian Society of Mechanical Sciences and Engineering, 34, 269-275 (2012). https://doi.org/10.1590/S1678-58782012000300007

[15] Li C., Browning A. R., Christensen S., Strachan A.: Atomistic simulations on multilayer graphene reinforced epoxy composites. Composites Part A: Applied Science and Manufacturing, 43, 1293-1300 (2012). https://doi.org/10.1016/j.compositesa.2012.02.015

[16] Wajid A. S., Ahmed H. S. T., Das S., Irin F., Jankowski A. F., Green M. J.: High-performance pristine graphene/ epoxy composites with enhanced mechanical and electrical properties. Macromolecular Materials and Engineering, 298, 339-347 (2012). https://doi.org/10.1002/mame.201200043

[17] Jiang L., Shen X-P., Wu J-L., Shen K-C.: Preparation and characterization of graphene/poly(vinyl alcohol) nanocomposites. Journal of Applied Polymer Science, 118, 275-279 (2010). https://doi.org/10.1002/app.32278

[18] Yang X., Wang Z., Xu M., Zhao R., Liu X.: Dramatic mechanical and thermal increments of thermoplastic composites by multi-scale synergetic reinforcement: Carbon fiber and graphene nanoplatelet. Materials and Design, 44, 74-80 (2013).

https://doi.org/10.1016/j.matdes.2012.07.051

[19] Chatterjee S., Wang J. W., Kuo W. S., Tai N. H., Salzmann C., Li W. L., Hollertz R., Nüesch F. A., Chu B. T. T.: Mechanical reinforcement and thermal conductivity in expanded graphene nanoplatelets reinforced epoxy composites. Chemical Physics Letters, 531, 610 (2012). https://doi.org/10.1016/j.cplett.2012.02.006

[20] Xie F., Qi S. H., Wu D.: A facile strategy for the reduction of graphene oxide and its effect on thermal conductivity of epoxy based composites. Express Polymer Letters, 10, 470-478 (2016).

https://doi.org/10.3144/expresspolymlett.2016.45 
[21] Sreeprasad T. S., Samal A. K., Pradeep T.: Tellurium nanowire-induced room temperature conversion of graphite oxide to leaf-like graphenic structures. Journal of Physical Chemistry C, 113, 1727-1737 (2009).

https://doi.org/10.1021/jp8084777

[22] Laachachi A., Vivet A., Nouet G., Ben D. B., Poilâne C., Chen J., Bai J. B., Ayachi M. H.: A chemical method to graft carbon nanotubes onto a carbon fiber. Materials Letters, 62, 394-397 (2018).

https://doi.org/10.1016/j.matlet.2007.05.044

[23] Acar V., Akbulut H., Sarıkanat M., Seydibeyoğlu M. Ö., Seki Y., Erden S.: Enhancement of interface mechanics of carbon fiber reinforced prepreg composites with carbon nanostructures (In Turkish). Electronic Journal of Machine Technologies, 10, 43-51 (2013).

[24] Huntsman: Araldite ${ }^{\circledR}$ LY 1564/Aradur ${ }^{\circledR}$ 3486/Aradur ${ }^{\circledR}$ 3487 product data sheet. (2012).

[25] Jiang S., Li Q., Wang J., He Z., Zhao Y., Kang M.: Multiscale graphene oxide-carbon fiber reinforcements for advanced polyurethane composites. Composites Part A: Applied Science and Manufacturing, 87, 1-9 (2016). https://doi.org/10.1016/j.compositesa.2016.04.004

[26] Li J., Huang Y., Xu Z., Wang Z.: High-energy radiation technique treat on the surface of carbon fiber. Materials Chemistry and Physics, 94, 315-321 (2005). https://doi.org/10.1016/j.matchemphys.2005.05.007

[27] Tyson B. M., Al-Rub R. K. A., Yazdanbakhsh A., Grasley Z.: A quantitative method for analyzing the dispersion and agglomeration of nano-particles in composite materials. Composites Part B: Engineering, 42, 1395-1403 (2011). https://doi.org/10.1016/j.compositesb.2011.05.020

[28] Ma P-C., Mo S-Y., Tang B-Z., Kim J-K.: Dispersion, interfacial interaction and re-agglomeration of functionalized carbon nanotubes in epoxy composites. Carbon, 48, 1824-1834 (2010). https://doi.org/10.1016/j.carbon.2010.01.028

[29] Garcia M. G., Marchese J., Ochoa N. A.: Effect of the particle size and particle agglomeration on composite membrane performance. Journal of Applied Polymer Science, 118, 2417-2424 (2010).

https://doi.org/10.1002/app.32274

[30] Jiang S., Gui Z., Bao C., Dai K., Wang X., Zhou K., Shi Y., Lo S., Hu Y.: Preparation of functionalized graphene by simultaneous reduction and surface modification and its polymethyl methacrylate composites through latex technology and melt blending. Chemical Engineering Journal, 226, 326-335 (2013). https://doi.org/10.1016/j.cej.2013.04.068

[31] Wu C-K., Wang G-J., Dai J-F.: Controlled functionalization of graphene oxide through surface modification with acetone. Journal of Materials Science, 48, 34363442 (2013).

https://doi.org/10.1007/s10853-012-7131-6
[32] Gudarzi M. M., Sharif F.: Enhancement of dispersion and bonding of graphene-polymer through wet transfer of functionalized graphene oxide. Express Polymer Letters, 6, 1017-1031 (2012).

https://doi.org/10.3144/expresspolymlett.2012.107

[33] Saelhoff A-K., Wilms C., Warnecke M., Pico D., Sernecki M., Seide G. H., Gries T.: Matrix/fibre boundary layer in fibre reinforced plastics: Characterization of the adhesion. Chemical Engineering Transactions, 32, 1633-1638 (2013). https://doi.org/10.3303/CET1332273

[34] Demir A., Seki Y., Bozaci E., Sarikanat M., Erden S., Sever K., Ozdogan E.: Effect of the atmospheric plasma treatment parameters on jute fabric: The effect on mechanical properties of jute fabric/polyester composites. Journal of Applied Polymer Science, 121, 634-638 (2011).

https://doi.org/10.1002/app.33220

[35] Sever K., Sarikanat M., Seki Y., Erkan G., Erdoğan U. H., Erden S.: Surface treatments of jute fabric: The influence of surface characteristics on jute fabrics and mechanical properties of jute/polyester composites. Industrial Crops and Products, 35, 22-30 (2012). https://doi.org/10.1016/j.indcrop.2011.05.020

[36] Zhang X., Fan X., Yan C., Li H., Zhu Y., Li X., Yu L.: Interfacial microstructure and properties of carbon fiber composites modified with graphene oxide. ACS Applied Materials and Interfaces, 4, 1543-1552 (2012). https://doi.org/10.1021/am201757v

[37] Li W., Yue Y. Z., Wang M. Y., Li Q., Ren R.: Using maleic anhydride functionalized graphene oxide for improving the interfacial properties of carbon fiber/BMI composites. Express Polymer Letters, 10, 874-882 (2016).

https://doi.org/10.3144/expresspolymlett.2016.82

[38] He P., Huang B., Liu L., Huang Q., Chen T.: Preparation of multiscale graphene oxide-carbon fabric and its effect on mechanical properties of hierarchical epoxy resin composite. Polymer Composites, 37, 1515-1522 (2016).

https://doi.org/10.1002/pc.23321

[39] da Silva L. V., Almeida J. H. S., Angrizani C. C., Amico S. C.: Short beam strength of curaua, sisal, glass and hybrid composites. Journal of Reinforced Plastics and Composites, 32, 197-206 (2013). https://doi.org/10.1177/0731684412467561

[40] Brown J. R., Mathys Z.: Plasma surface modification of advanced organic fibres: Part V Effects on the mechanical properties of aramid/phenolic composites. Journal of Materials Science, 32, 2599-2604 (1997). https://oi.org/10.1023/A:1018654501851

[41] Kim S-K., Kim J. T., Kim H-C., Rhee K-Y., Kathi J.: Thermal and mechanical properties of epoxy/carbon fiber composites reinforced with multi-walled carbon nanotubes. Journal of Macromolecular Science Part B: Physics, 51, 358-367 (2012). https://doi.org/10.1080/00222348.2011.596799 